\title{
Escrituras seudónimas, lacerías clandestinas. El insilio de Rubén Sotoconil
}

\author{
Pseudonymous writings, clandestine ties. The insilium of Rubén Sotoconil
}

\author{
Araucaria Rojas Sotoconil ${ }^{*}$
}

\begin{abstract}
Resumen: Este escrito procura indagar de qué modo se materializaron los efectos del exilio interior en el actor y militante comunista Rubén Sotoconil. Con este objetivo, se exploran sus estrategias para resistir los horrores dictatoriales y se confiere especial atención a la creación del "Teatro Familiar de Barrio" y a su producción escritural presente en "Revista Araucaria de Chile". ¿Cómo se encarna y cobra vida el insilio en un caso particular? es la pregunta a la que se aspira dar contestación. Para ello, las fuentes visitadas son Revista Araucaria, manuscritos, epístolas, fotografías y apuntes; además de la bibliografía general referida a la producción teatral en el contexto autoritario.
\end{abstract}

Palabras claves: Exilio interior, Insilio, Teatro en dictadura, Revista Araucaria de Chile.

\begin{abstract}
This paper seeks to investigate how the effects of internal exile materialized in the actor and communist militant Rubén Sotoconil. With this objective, their strategies to resist the dictatorial horrors are explored and special attention is given to the creation of the "Teatro Familiar de Barrio" and to its scriptural production present in "Revista Araucaria de Chile". How does insilio incarnate and come to life in a particular case? Is the question that seeks to answer. For this, the sources visited are Araucaria Magazine, manuscripts, epistles, photographs and notes; In addition to the general bibliography referring to theatrical production in the authoritarian context.
\end{abstract}

Keywords: Inner exile, insilio, Theater in dictatorship, Magazine Araucaria of Chile.

Recibido: $05 / 06 / 2017$

Aceptado: 24/07/2017

* Chilena. Licenciada en Historia de la Pontificia Universidad Católica de Chile. Estudiante de Magister en Historia Universidad de Santiago. lacalandriasemefue@gmail.com 
Es consabido que partir del golpe de Estado acaecido en septiembre de 1973, comenzó la diáspora forzosa de miles de chilenos que debieron migrar hacia distintos lugares del orbe. Concomitante a ello, dentro del territorio se produjo un fenómeno íntimo, casi indistinguible, de exigua atención investigativa: el exilio interior. Se hicieron patentes desde entonces torturas, desapariciones, exoneración laboral, propagación de listas negras y la clandestinización de las actividades políticas. Clausura y recogimiento de la vida tal como era concebida.

\section{La vida}

Rubén Sotoconil nació un 4 de abril de 1917 en Trupán, un pequeño pueblo en la región del Bío-Bío. Hijo del fotógrafo y Director de la Escuela de Antuco Armando Sotoconil Ramírez y de la dueña de casa Liduvina Aranda, quienes contrajeron matrimonio en 1908 en la localidad de Loncoche.

Cursó su educación primaria en Mulchén y luego se trasladó a realizar las Humanidades al Liceo de Hombres de Los Ángeles. Allí lo conmovió hasta lo más hondo, la matanza de por lo bajo- doscientos campesinos y mapuche en la zona de Lonquimay ocurrida en 1934, conocida como Masacre de Ránquil ${ }^{1}$. Ocultó a Zurita, uno de los líderes campesinos en su casa, redactó y repartió panfletos que arengaban a protestar contra lo sucedido. Fue delatado y con posterioridad trasladado a la cárcel de Concepción, donde se encontró con obreros de Lota en huelga de hambre, a la que, sin vacilar, suscribió. Todos esos acontecimientos lo marcarían a fuego, para allegarse desde entonces y a perpetuidad a las filas del Partido Comunista de Chile $^{2}$.

Fue expulsado del Liceo y se vio conminado a finalizar sus estudios en San Fernando. Migró a Santiago en 1937, estudió un año Ingeniería en la Universidad de Chile, pero por asuntos económicos debió desertar y buscar trabajo. Se ofició entonces como libretista, locutor de radio y realizó sus primeras incursiones en radioteatro en las emisoras Agricultura, Cooperativa Vitalicia, Del Pacífico. En 1940 se inscribió en el Instituto Pedagógico, donde cursó Inglés y Filosofía en paralelo, mientras impartía a su vez, clases en los liceos Barros Borgoño y José Victorino Lastarria.

Ese mismo año se hace parte fundamental de la inquietud universitaria de renovar el teatro chileno de entonces al vincularse con otros estudiantes en el Teatro Experimental, heredero del CADIP (Centro de Arte Dramático del Instituto Pedagógico) fundado en 1934 por Pedro de la Barra ${ }^{3}$. La visita de la compañía española de Margarita Xirgú en 1937, inspiró también a este movimiento teatral, que se presentó por entonces vanguardista, iconoclasta y

\footnotetext{
${ }^{1}$ Ver Patricio Manss, Las Grandes Masacres. Ed. Quimantú, Colección Nosotros Los Chilenos, Santiago, 1973. Reinaldo Lomboy, Ranquil. Ed. Orbe, Santiago, 1942. Olga Ulianova "El levantamiento campesino de Lonquimay y la Internacional Comunista", Revista Estudios Públicos, Nº 89, Santiago, 2003.

${ }^{2}$ Lina Zapata, Ocho vidas para ser actuadas, Santiago: Ed. Hernán Godoy, 2003, p. 30.

${ }^{3}$ Ruben Sotoconil, 20 años de Teatro Experimental, Caracas: Ed. Gráficas Internacional, 1991, p. 38
} 
comprometido, en tanto proponía dotar de nuevos bríos al arte escénico local. Procuraron organizar un nuevo público teatral, crear un Teatro-Escuela, difundir autores clásicos y modernos; todo ello acompañado de las esperanzas que encarnaba el gobierno del Frente Popular. Este movimiento teatral decantó en la primera Escuela de Teatro profesional chilena, que funcionó estrenando obras de forma ininterrumpida entre 1941 y 1962.

Desde 1943 trabajó como reportero y secretario de redacción del diario "El Siglo” y entre 1951 y 1955 dirigió la revista "Nuestro Tiempo", sobre política y marxismo internacional, que llegó a tener un tiraje de once mil ejemplares y repartirse por toda América Latina. Se desempeñó además como profesor en las cátedras de Historia del Teatro, Crítica Dramática, Voz y Maquillaje. En 1960 se publicó su traducción a los "Manuscritos económicos y filosóficos" de Karl Marx ${ }^{4}$ y en 1961 filmó "Deja que los perros ladren" versión cinematográfica de la obra de Sergio Vodanovic dirigida por Naum Kramarenco, donde la crítica destacó su actuación como funcionario público ${ }^{5}$. El mismo año viajó como emisario del Partido con el Conjunto Cuncumén a una gira por la Unión Soviética, donde visitaron Polonia, Checoslovaquia, Rumania, Bulgaria, entre otros sitios.

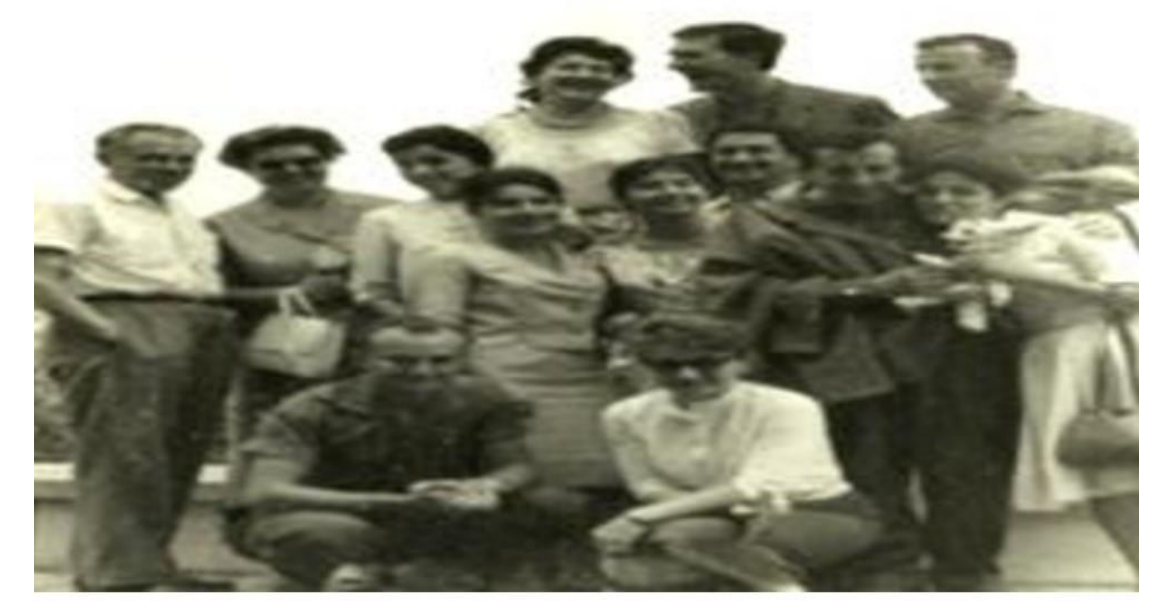

Conjunto Cuncumén en viaje a la U.R.SS retratado por Rubén Sotoconil. Fuente: Archivo personal de Rubén Sotoconil.

Entre 1963 y 1964, Rubén y su familia viajaron a China, donde fueron recibidos en un banquete por el propio Mao Tzedong ${ }^{6}$. Allí se ofició como traductor del periódico "Pekín Informa" y estrechó relaciones con su perenne camarada, el escritor Francisco Coloane y su esposa Eliana Rojas, además de otros destacados personeros de la delegación chilena. Según sus propias palabras "al año de estadía tuvimos que volvernos, ya que China cesa su

\footnotetext{
${ }^{4}$ Ver Karl Marx, Manuscritos económicos y filosóficos, Santiago: Ed. Austral, 1960

5 "Deja que los perros ladren", Última Hora, Santiago, 1961, p. 2

${ }^{6}$ Entrevista a Mireya Moreno, realizada 3 de marzo de 2016.
} 
amistad con Rusia y comienzan a hostigarnos a raíz de nuestras ideas políticas. Nos abrían las cartas, etc., afortunadamente el hostigamiento era sólo a nivel laboral y no particular"7

A su regreso trabaja en la obra "La casa vieja", dirigida por su amigo Víctor Jara y en 1969- mismo año en que renuncia al Teatro de la Universidad de Chile- desempeña el rol de carabinero en el insigne film "El Chacal de Nahueltoro" de Miguel Littin. Todos los quehaceres, se ven propulsados y atravesados por un Partido que ya para entonces, le era omnímoda.

\section{La Unidad Popular}

El férreo compromiso político que acompañó a Rubén Sotoconil durante toda su vida, lo hizo participar de forma activa en todas las campañas presidenciales de Salvador Allende ${ }^{8}$. Suscribió con ímpetu en el proceso de campaña de la que sería la culminación de un extenso periplo emprendido muchos años antes por la izquierda chilena: el periodo de la Unidad Popular, acontecido entre 1970-1973. Se afirmó entonces una voluntad política transformadora, en la que se enuncia rotundamente: "las aspiraciones sociales del pueblo chileno son legítimas y posibles de satisfacer" ". El cambio que se atisbó posible, emergió en concomitancia con la dislocación de la trama societal tal y como era conocida, a partir de una serie de reformas que son implementadas, profundizadas: reforma agraria, al cobre, a la banca privada. Se constata una participación inusitada de movimientos y actores sociales, la concreción de lo que parecía improbable, imposible; descrita en palabras de la historiadora María Angélica Illanes:

Desde el ámbito social y cultural, así como desde la política económica y social civil y gubernamental, todo tiende a confluir y entretejerse con la existencia real del pueblo, con el "cuerpo del pueblo" considerado como encarnación de la ética y de la práctica política, social, económica y cultural ${ }^{10}$

Los relatos sobre este proyecto, oscilan, por un lado, entre su caracterización carnavalesca, alegre; y por otro, su cristalización como episodio luctuoso y fatal. Ello, en el campo cultural cobra un sentido intenso, en tanto el Programa fundacional proclamaba "una cultura nueva para la sociedad" y el acceso "de las masas para ejercer su derecho a la cultura"11. En este sentido, germina la Editorial Quimantú, la Discoteca del Cantar Popular (DICAP); además de experiencias irreplicables como el Tren de la Cultura ${ }^{12}$, los Balnearios Populares, la Operación Saltamontes además de renovaciones estéticas en la música, teatro, cine, plástica, como patentes expresiones de compromiso y militancia política. En este álgido y esperanzador piélago, Rubén Sotoconil en 1970 migra a Valdivia con objeto de

\footnotetext{
${ }^{7}$ Entrevista a Rubén Sotoconil, realizada por Priscilla Gutiérrez, febrero 2002

${ }^{8}$ Ver Anexo. Mario Amorós, Allende. La Biografía, Santiago: Eds. B, 2013, p. 571

${ }^{9}$ Programa básico Unidad Popular, Santiago: Ed. Patria Nueva, 1971, s/p.

${ }^{10}$ María Angélica Illanes, "El cuerpo nuestro de cada día": El pueblo como experiencia emancipatoria en los tiempos de la Unidad Popular" en Julio Pinto ed., Cuando hicimos historia: La experiencia de la Unidad Popular, Santiago: Ed. LOM, 2005, p.127

${ }^{11}$ Programa básico Unidad Popular. op. Cit.

${ }^{12}$ Cesar Albornoz, "La cultura en la Unidad Popular: Porque esta vez no se trata de cambiar un presidente" en Julio Pinto, ed., Cuando hicimos historia: La experiencia de la Unidad Popular, Santiago: Ed. LOM, 2005, p. 156
} 


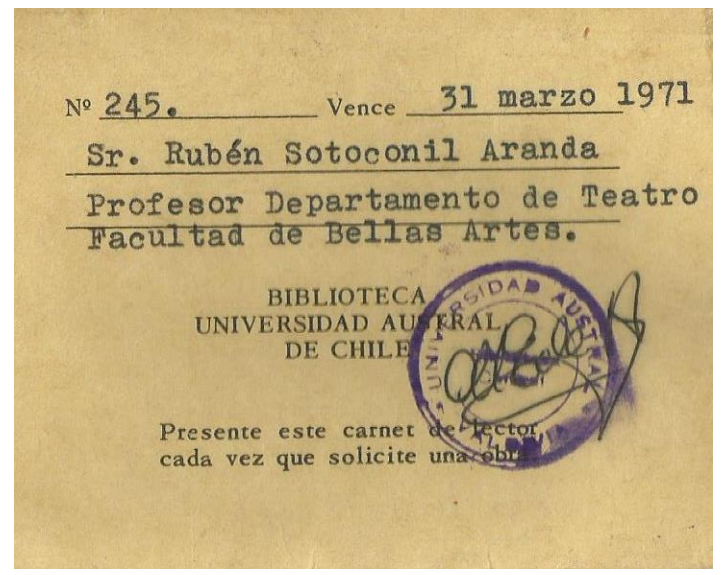

fundar y dirigir la Escuela de Teatro de la Universidad Austral de Valdivia, donde deja su profundo legado, palpable hasta el día de hoy ${ }^{13}$.

\author{
Carnet de docente de Departamento de Bellas Artes \\ Universidad Austral. \\ Fuente: Archivo personal de Rubén Sotoconil.
}

La Unidad Popular significó para Sotoconil la consagración de una lucha que, para entonces, le era añosa y añorada. Era la encarnación de un proceso que llegaba a su apogeo, la antigua esperanza revolucionaria que por fin se hacía carne. En 1972 filmó la paradigmática película de Aldo Francia "Ya no basta con rezar" en el que interpretó a un dirigente sindical y entre 1971 y 1972 escenificó junto a la compañía de Ana González la obra "Mantis Religiosa" de Alejandro Sieveking y "Teatromascope" de José Pineda. Obras que se convirtieron con el tiempo, en fotografías, imágenes y voces modélicas de su época. Desde 1972 se desempeñó como director de la Revista "Talleres de la Cultura" de la Universidad Técnica del Estado UTE, donde trabajó hasta el golpe de septiembre del '73. Las transformaciones parecieron excedidas a quienes urdieron el golpe. No se detallará en pormenores, mas, lo que emerge eminente, es que la marejada de renovación, era de allí en adelante prohibida, acallada con radicalidad. Así, también la voz de Sotoconil, enmudecida.

Revista dirigida por Rubén Sotoconil. Fuente: La UTE vive. Memorias y testimonios de la reforma universitaria en la Universidad Técnica del Estado. Chile 1961/197314

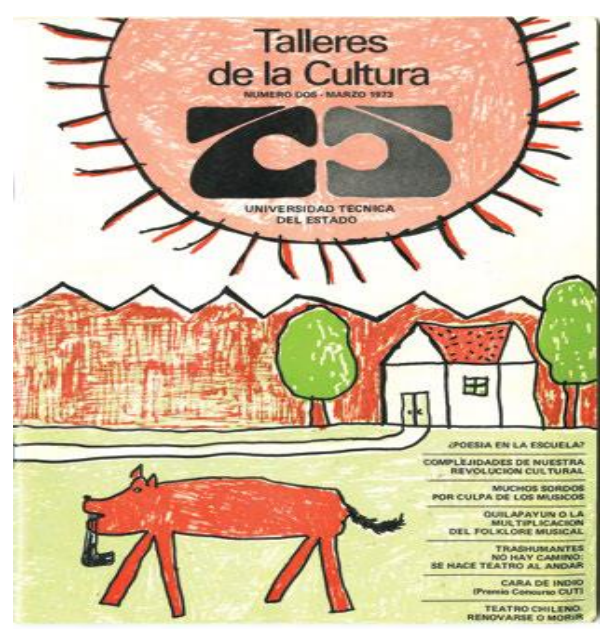

El exilio interior

\title{
i. Los primeros años de la dictadura
}

Comienza temprano, un extenso derrotero represivo que manifiesta sus distintos carices. El extrañamiento impuesto y masivo de chilenos provoca un quiebre vital para sus víctimas, despojo del territorio y con él, de hábitos, afectos y cotidianeidad. Se dispone la expulsión de individuos que comportaran un 'peligro para la seguridad' y se crean como contraparte, organizaciones de diversa índole que tenían por objeto propiciar la reinserción de los eventuales retornados. Relevantes en este accionar, fueron la Vicaría de la

\footnotetext{
${ }^{13}$ Ver Sibila Sotomayor, "Una escena truncada: historia de la Escuela de Teatro de la Universidad Austral de Chile (19701976)”, Revista Panambí, №2, Valparaíso, 2016.

14 Tomás Ireland y Francisco Rivera eds., La UTE vive. Memorias y testimonios de la reforma universitaria en la Universidad Técnica del Estado. Chile 1961/1973, Santiago: Ed. USACH, 2016, p. 227
} 
Solidaridad, la Fundación de Ayuda Social de las Iglesias Cristianas (FASIC), entre otras ONG e instituciones ${ }^{15}$. Se funda bajo ese alero, un nuevo tiempo creador, poroso y dialogante, donde cabía la confraternidad y la acción colectiva.

Paralelo a este destierro material, se genera un proceso dentro del territorio que se ha denominado exilio interior o insilio, definido como la existencia "cautiva y marginada en sus propias entrañas físicas"16 que según Miguel Salabert, implica un "autismo social"17. Misma idea sostiene Hugo Cancino, para quien es "la paradoja existencial de estar y de permanecer allí en el espacio físico e imaginario de una cultura nacional y de una lengua, sin participar, al margen de un sistema impuesto y de sus valores, viviendo la existencia en soledad" 18 . Volodia Teitelboim, en tanto, definió a los insiliados como personas "que no se movieron de su país, pero a los cuales pretendieron convertirlos en seres despreciables, gente de tercera clase" ${ }^{\text {"19 }}$. Como matiz a lo que sostienen esos autores, el insilio además de ser la atomización, el olvido y el repliegue forzoso, es también -y, sobre todo- la creación de nuevas posibilidades de enunciación y articulación común. Se ocupa el lugar de la clandestinidad como única vía de desplegar estrategias de resistencia y de sortear el horror. El punto de fuga de la represión.

Tarjeta de difusión Comité Pro- Retorno Exiliados. Fuente: Archivo personal de Rubén Sotoconil

En concomitancia a este dolorido proceso, se desplegó una política cultural de impronta autoritaria. El estudioso de las artes escénicas Juan Villegas, es enfático al explicar que existía entonces una "censura implícita o indirecta, la presión económica, el exilio político o económico o la reinstitucionalización de compañías teatrales"20. Por su reconocida y pública

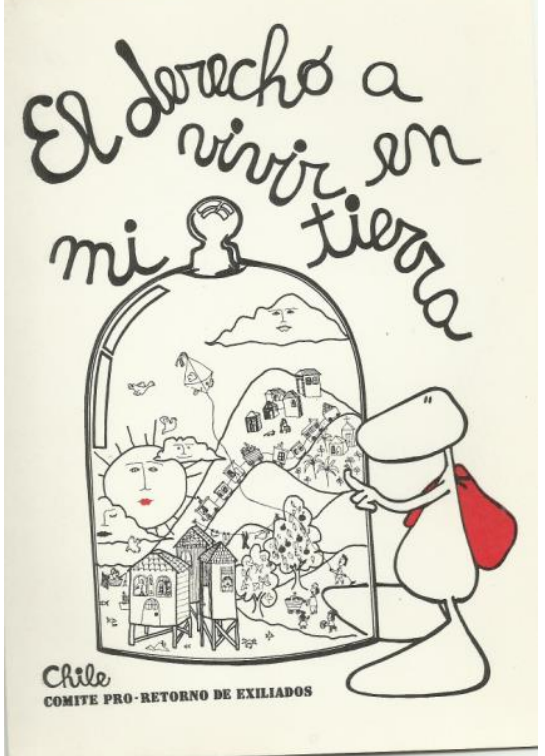
adscripción al Partido Comunista, tras el golpe de 1973, Rubén Sotoconil -como muchos otros artistas- fue acosado y vetado por medio de la promulgación de 'listas negras' que traficaban de modo subrepticio por los canales de televisión y radios. Según relató con sus propias palabras:

\footnotetext{
15 Norambuena, Carmen. "El exilio chileno río profundo de la cultura Iberoamericana", Revista Sociohistórica: Cuadernos del Cish, Buenos Aires, 2008, p. 175 y ss.

${ }^{16}$ Miguel Salabert, El exilio interior, Barcelona: Ed. Anthropos, 1988

${ }^{17}$ Ibid., p. 11

${ }^{18}$ Hugo Cancino, "Exilio, chileno e historia. Contribución a un debate sobre los problemas teórico- metodológicos de una investigación historiográfica sobre nuestro exilio". En Centro de estudios Miguel Enríquez, Santiago, 2000, p. 2

${ }^{19}$ Volodia Teitelboim, En el país prohibido, Santiago: Ed. Sudamericana, 1998, p. 41

${ }^{20}$ Juan Villegas, "Discursos teatrales en Chile en la segunda mitad del siglo XX" en Heidrun Adler, et. Al., Resistencia y poder. Teatro en Chile, Madrid: Ed. Iberoamericana, 2000, p. 22
} 
El canal 13 me ofreció un papel en una telenovela y cuando me presenté el director me dijo con lágrimas en los ojos que no podía actuar. Vivíamos con mi familia en una tensión insoportable. Pero ni siquiera entonces oculté mi ideología ni mi militancia en el Partido Comunista. He dado la cara siempre. Nunca he renunciado a mi libertad ${ }^{21}$.

El investigador Oscar Lepeley, refrendando las palabras de Sotoconil, indica el procedimiento y su temprana ejecución:

Listas negras se habían distribuido para prohibir el trabajo en los medios de comunicación de una gran cantidad de actores y gente de teatro. Ya en diciembre de 1973 el Sindicato de Actores de Teatro, Radio y Televisión (SIDARTE), constatan que el $90 \%$ de los actores chilenos estaban cesantes y que el $25 \%$ se había ido al extranjero 22

La cesantía, como a buena parte de la sociedad, arreciaba a la familia Sotoconil- Moreno. Ante la hostilidad de los acontecimientos, decidieron dedicarse a labores nunca antes exploradas: la venta de ropa usada. Para ello implementaron un precario puesto en Plaza Egaña, con objeto de, además, recaudar fondos para familiares de detenidos y los mismos asilados. Entretanto, dos células del Partido Comunista (de Rubén Sotoconil y su esposa

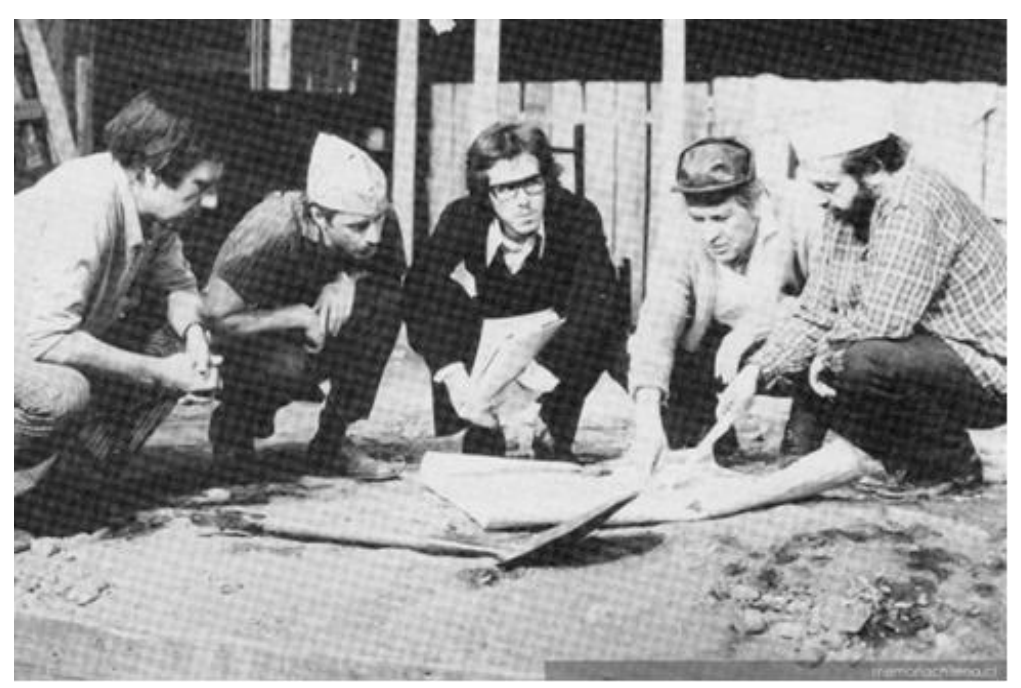
Mireya Moreno) continuaban activando de forma permanente en su residencia de la Reina, sin comunicación entre sí. Mireya Moreno, actriz y esposa de Sotoconil trabajó sin cesar en comisiones de cultura y asilo $^{23}$, ocultando a muchos militantes en su hogar.

Obra de Teatro "Pedro, Juan y Diego", Teatro ICTUS. Rubén Sotoconil, el segundo a la derecha. Fuente: www.memoriachilena.cl

En 1976 Rubén Sotoconil se integra al Teatro Ictus, en la obra "Pedro, Juan y Diego" del autor David Benavente. Ella se presenta como una pieza paradigmática del periodo, en tanto aborda temáticas "histórico- contingentes"24 como la cesantía y la necesidad de

\footnotetext{
${ }^{21}$ Entrevista a Rubén Sotoconil, realizada por Priscilla Gutiérrez, febrero 2002

${ }^{22}$ Oscar Lepeley, "Avatares del teatro chileno contestatario durante los primeros años de la dictadura militar" en Heidrun Adler, et. Al., Resistencia y poder. Teatro en Chile, Madrid: Ed. Iberoamericana, 2000, p. 113

23 Ver relatos de Mireya Moreno en Elisabeth Prudant, $Y$ entonces estaban ellas. Memoria $(s)$ de las Mujeres Democráticas durante la dictadura, Santiago: Ed. Ceibo, 2013

${ }^{24}$ María de la Luz Hurtado y Carlos Ochsenius, Teatro Ictus, Santiago: Ed. CENECA, p. 77
} 
mantener la dignidad. El éxito de público la mantuvo dos años en cartelera producto de su perspicaz sentido del humor y sobre todo, por su condición de sagaz crítica social" 25 .

\section{ii. El Teatro Familiar de Barrio}

Las condiciones recrudecían y a partir de la necesidad de expresar lo que sucedía, se fundaron nuevas instancias de comunicación y reunión. Como señala Fernando Alegría, "los años han pasado, sin embargo, la carga viva del exilio interior ya ha comenzado a entregar sus voces"26.

Florecen y se fortalecen espacios de resistencia a la dictadura, alternativas artísticas, políticas y académicas vigorizan sus redes y espacios. La Agrupación Cultural Universitaria, Nuestro Canto, Alerce, Músicos jóvenes, Taller 666, La Bicicleta, SUR, CENECA' distintas peñas y boletines, son algunas de las agrupaciones que aglutinan diversas y amplias voluntades de desobediencia a la dictadura.

Asimismo, el advenimiento de los años '80 constituyó un cambio en el lenguaje y estética del teatro chileno, como también en las condiciones materiales en las que éste se desenvolvía. Acorde con las políticas económicas prontas a consolidarse, en 1980 se aplicó el IVA al teatro chileno ${ }^{27}$, la institucionalidad fue cooptando compañías teatrales ${ }^{28}$ y se fue masificando un circuito de "teatro comercial". En palabras de Grinor Rojo "el espíritu universitario, que el Teatro de la Chile procuró mantener a lo largo de tres décadas de espléndido trabajo, hoy brilla por su ausencia" 29 . Contemporáneamente, se desarrollaban compañías independientes de profunda relevancia: Imagen, Los Comediantes, El Telón, El Aleph y el propio Ictus $^{30}$ se configuraron como espacios artísticos de resistencia. Las tramas de un teatro poblacional, aficionado, popular y colectivo siguen articulándose en inimaginables espacios, como iglesias y poblaciones donde se observa una patente "ausencia de conceptos abstractos" $"$. A diferencia de otros movimientos culturales como el Canto Nuevo, el teatro parecía escabullirse de las metáforas para, por el contrario, entregar un mensaje que pareciera llano e inteligible

En 1980 Rubén Sotoconil fue elegido Presidente del Sindicato de Actores SIDARTE y desde ese lugar, continuó desarrollando su trabajo político, denunciando el exilio, vejaciones, censura y marginación de algunos actores. Énfasis en los derechos humanos, acciones artísticas comprometidas con presos políticos y campañas solidarias, fueron algunas ocupaciones del Sindicato por entonces.

\footnotetext{
${ }^{25}$ Ibid.,p. 78

${ }^{26}$ Fernando Alegría, "La novela chilena del exilio interior", en Rev. Chilena de literatura, $\mathrm{N}^{\circ} 42$ Santiago, 1993, p. 1

${ }^{27}$ Oscar Lepeley, op. cit., p. 118

${ }^{28}$ Juan Villegas, op. cit., p. 22

${ }^{29}$ Grinor Rojo, "Teatro chileno bajo el fascismo" en Rev. Araucaria de Chile, Madrid: Ed. Michay, n 22, 1983, p. 128

${ }^{30}$ Ibid., p. 128 y ss.

${ }^{31}$ Diego Muñoz, “Teatro poblacional chileno (1978 1983)” en Rev. Araucaria de Chile, Madrid: Ed. Michay, n 31, 1985, p. 136
} 


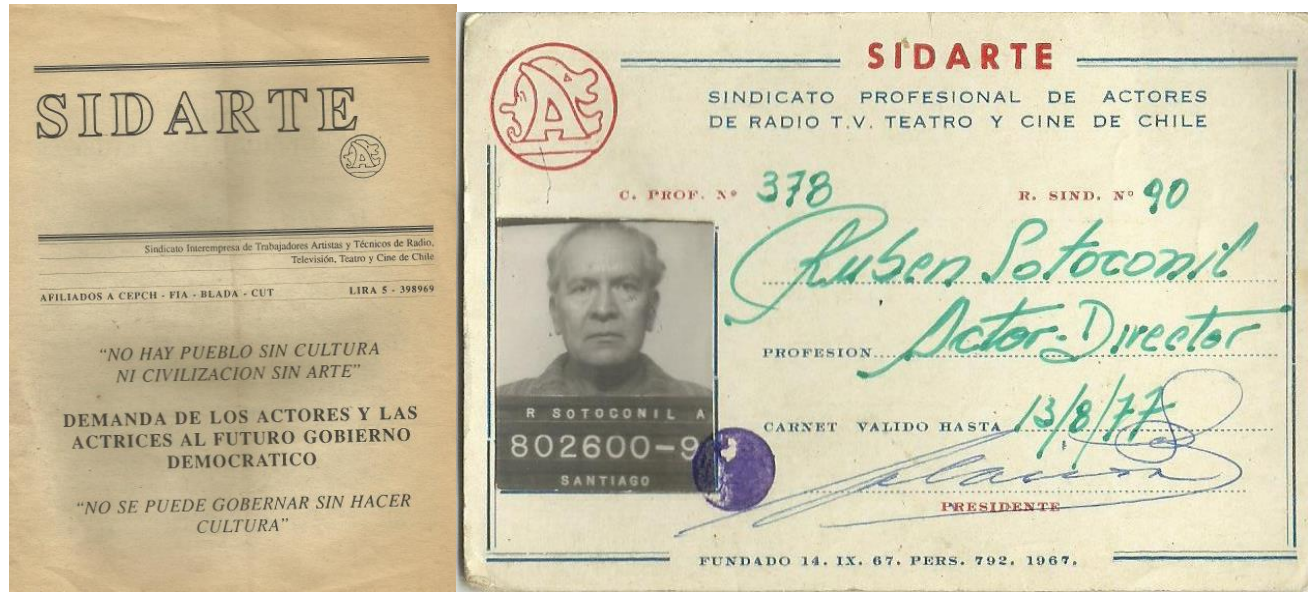

Folletín carnet de SIDARTE. Fuente: Archivo personal de Rubén Sotoconil

En la senda de afianzar el lazo del teatro y la labor política, en 1981 se materializó una inquietud que Sotoconil magullaba con insistencia: cómo devolver el teatro a la gente. Bajo esta convicción, acompañado de amigos y su esposa Mireya Moreno, fundó el Teatro Familiar de Barrio TEFABA ${ }^{32}$, iniciativa que procuraba realizar funciones en poblaciones, sindicatos, centros comunitarios, parroquias e incluso, casas particulares. Sotoconil planteaba que el teatro tenía una potencia remecedora, que podía operar como forma de expresión, crítica y resistencia a la dictadura. El TEFABA montó "El temor a las bofetadas" de Georges Courteline; "Terror y Miseria del Tercer Reich" de Bertolt Brecht; "José Domingo Gómez Rojas" de Alfonso Álvarez; otros autores chilenos, creaciones colectivas y también distintas lecturas dramatizadas de poesía política.

En 1984 retornó del exilio Víctor Calderón, quien escribió para el Teatro Familiar de Barrio la obra "Regreso...jAl fin!" tratando el tema del destierro. La conmoción en los espectadores se manifestaba de distintas formas: llantos, discusiones, poemas y arpilleras brotaban tras la representación ${ }^{33}$. Luego de cada función se cedía la palabra y se abría la discusión sobre una multiplicidad de temas en boga, como la cesantía, la tortura y la represión, acompañada de un austero ágape que la amenizara. Muchas veces, estas presentaciones constituían una primera aproximación de los pobladores al teatro, quienes se veían interpelados de forma radical. En voz de Elsa Rosales, de La Pintana:

Mirando la labor de este teatro uno se preguntaba. ¿y dónde estoy que no ayudo y no apoyo? ¿qué puedo hacer yo? (...) Este grupo fue una vanguardia, digamos grande y buena porque llegó a la gente precisa, a los que tenían que llegar, no fue un teatro

\footnotetext{
${ }^{32}$ Sobre el Teatro Familiar de Barrio ver Christian García Medel, El rol sociopolítico del teatro durante el Régimen Militar, Tesis para optar al grado de periodista Universidad Academia de Humanismo Cristiano, Santiago, 2011

${ }^{33}$ María de la Fuente, Teatro Familiar de Barrio: Una experiencia de lucha, Santiago: Imp. Walter Letelier, 2002, p. 68
} 
cerrado o solo para un selecto grupo de amistades fue un teatro abierto y así también llegó a todos. Eso fue lo más hermoso ${ }^{34}$

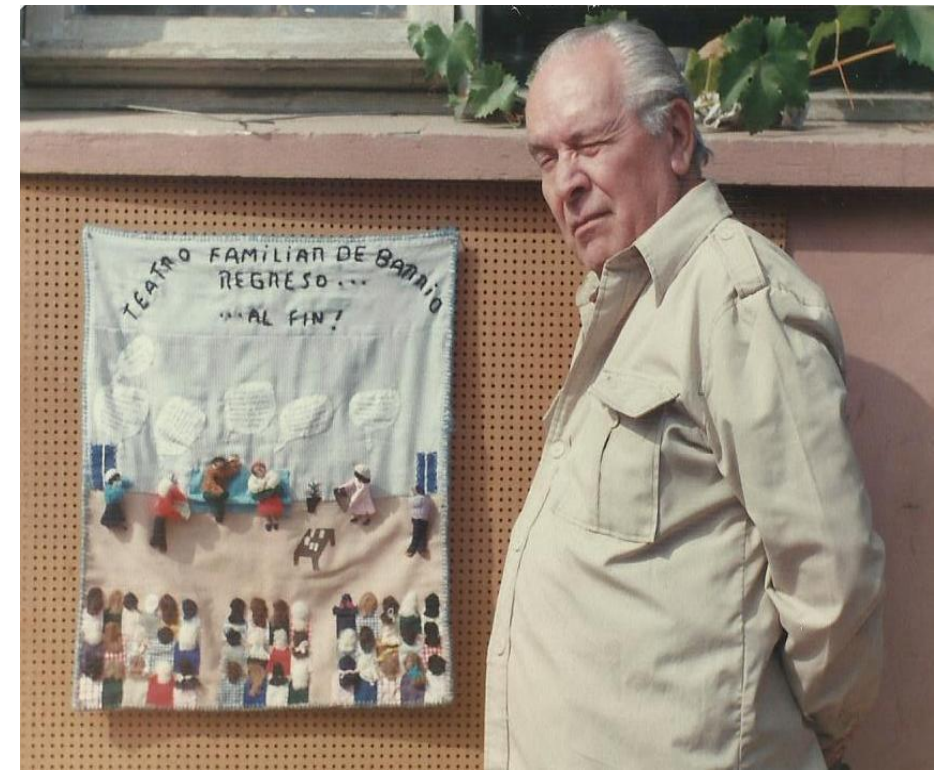

Rubén Sotoconil y la arpillera entregada por pobladoras, basada en la obra “Regreso ¡Al fin!” de Victor Calderón. Fuente: Archivo personal de Rubén Sotoconil.

El Teatro Familiar de Barrio emergió como una necesidad inmanente, sin altas pretensiones artísticas y cuya aspiración primordial era llevar el teatro a la gente. Los actores aficionados que participaron en él, no se libraron de amenazas y amedrentamientos, no obstante, continuaron adelante con su afán. Leonardo Cohen, uno de ellos, rememora: "Una vez nos llegó por debajo de la puerta, a esta casa $^{35}$, un papel con unas amenazas terribles: 'Si ustedes siguen haciendo esto y hablando así de este gobierno nosotros los vamos a ir eliminando uno por uno a todos, para exterminar este grupo'. Decidimos continuar igual". 36

Fue en 1991, cuando esta fórmula de teatro popular comienza a perder su sentido fundacional. Rubén Sotoconil así lo expresó:

El teatro familiar fue nuestra actividad de resistencia a la dictadura durante 10 años consecutivos. Cuando Pinochet se vio obligado a retirarse de la Moneda, el grupo se disolvió bajo la ilusión de haber conquistado la democracia. Había cumplido con el objetivo de mantenernos vivos y ser un vínculo de comunicación y resistencia ${ }^{37}$.

\footnotetext{
${ }^{34}$ Citado en Ibid.,p. 251

${ }^{35}$ Se refiere a la casa particular de Rubén Sotoconil.

${ }^{36}$ Museo de la Memoria y los Derechos Humanos, Teatro Familiar de Barrio, Santiago: Museo de la Memoria y los Derechos Humanos, 2011.

${ }^{37}$ Ibid., p. 18
} 
Puede observarse de qué modo el asedio, el hostigamiento y el miedo como aristas del exilio interior, no significaron inmovilidad, sino por el contrario, espolearon la creación de nuevos espacios de enunciación y escenificación de la rebeldía. Como recuerda la actriz y esposa de Rubén Sotoconil Mireya Moreno, "Nuestro Teatro Familiar de Barrio, fue nuestra Barricada" ${ }^{38}$.

\section{iii La Revista Araucaria de Chile}

Las circunstancias dificultaban -es evidente- la divulgación masiva de medios de contra información o alternativos al imaginario dictatorial. La condición clandestina posibilitó la propagación de fórmulas diversas, no institucionales, anónimas y artesanales de comunicación. De este modo, la narrativa por ejemplo, fue generando "formas alegóricas, símbolos históricos del pasado, ambigüedad del discurso" "39, un locus ambivalente que se constituyó como nuevo espacio para la enunciación en el que la elipsis y la metáfora fueron recurrentes.

Las revistas culturales o literarias germinaron y operaron como "vehículo de expresión de sentimientos, de creación cultural, en fin, de contacto entre compatriotas" 40 quienes mantuvieron el vínculo por medio de su ejercicio intelectual y la sociabilidad política. Naín Nómez da cuenta de la relevancia que tienen en el campo literario, sobre todo en la difusión de poesía ${ }^{41}$, las revistas culturales "Literatura Chilena en el Exilio" y "Araucaria de Chile". La primera, dirigida por Fernando Alegría desde Estados Unidos y la segunda, por Volodia Teitelboim con sede en Madrid.

Araucaria si bien perteneció al Partido Comunista, no se instauró como espacio doctrinario ortodoxo y por el contrario, sus motores -en palabras de Carlos Orellana, su editor- fueron "la lucidez, el horror al dogma, el amor a la escritura y a su doble posibilidad de verdad y belleza"42. Participaron en ella Omar Lara, Hernán Loyola, Luis Alberto Mansilla y cientos de colaboradores que, desde todos los lugares del mundo, le dieron vida por medio de grabados, pinturas, artículos, reflexiones, críticas, cedidas todas de forma gratuita. Fue fundada en 1977 con sede primero en Paris y luego en Madrid, "desde entonces despliega regularmente un nuevo follaje cada tres meses. Con cada estación del año salen 224 hojas, que caen como mensajes de la cultura chilena y latinoamericana en las manos, ante los ojos, el espíritu de sus lectores, muchos de ellos compatriotas nuestros, repartidos por cincuenta países" $"$.

\footnotetext{
${ }^{38}$ Museo de la Memoria, Op. Cit.

${ }^{39}$ Norambuena Op. cit., 172

${ }^{40}$ Ibid., p. 174

${ }^{41}$ Naín Nómez, “Transformaciones de la poesía chilena entre 1973 y 1988” , Estudios filológicos, N 42, Valdivia, 2007, p. 6

${ }^{42}$ Carlos Orellana, Araucaria de Chile. Índice general (1978-1989), Santiago: Ed. Del Litoral, 1994, p. 16

${ }^{43}$ Volodia Teitelboim, Op. cit., p. 314
} 
La Revista "Araucaria de Chile" dio cuenta de un proceso de integración que se produjo de modo particular: por un lado, se editó en Europa, pero refería por completo acerca de Chile. Amplió asimismo el panorama desolador del primer tiempo de la dictadura y generó encuentros entre lugares distantes que, no obstante, compartían la misma realidad: la expatriación y el deseo de articular la solidaridad. Junto con ello, la revista se estableció como vínculo cultural entre exiliados, pero también como enlace entre insiliados que escribieron desde el anonimato. Figuras que como señaló Volodia Teitelboim operaban "como los peces, viven en las profundidades y navegan por aguas invisibles. Pero están en el fondo del buque, actuando en todo momento, captando cientos de comunicaciones, enviando mensajes inalámbricos, que se reciben a flor de agua o de tierra." 44

Rubén Sotoconil fue uno de los que devino pez invisible dentro del territorio chileno. Su relación con el exilio se desató desde el primer momento y se cristalizó en decenas de postales enviadas por amigas y camaradas, que atesoró en su archivo personal. Desolación expresada en fragmentos, desesperanzas musitadas, enclavadas en trozos de papel con destino a la que fue su tierra. Mismas trayectorias asumen distintos nombres que vocean atónitas. Rosario dice aún absorta: "Todo esto y muchísimo más quedó atrás. ¿Volverá? La vida dio un giro de $180^{\circ}$. Hay que aceptarlo. Pero es muy difícil aceptarlo y no volver permanentemente la vista atrás. Cuéntenme muchas cosas y saluden a la cordillera de parte mía, díganle que vivo con la esperanza de volver a verla"45. Carmen, en tanto expresa su desamparo: "Nada vale, sólo da dolor ver los testimonios aislados de algo que tuve: una casa. Entonces ¿qué me arraiga? ¿qué bienes defiendo? ¿qué pierdo o qué gano? Nada"46. Ana por su parte manifiesta "Converso con el dueño de casa y le cuento algunas impresiones de allá, es difícil, uno se aferra a las ideas que tiene, y ni yo misma puedo explicarme bien, pero lo único que deseo es volver allá" 47 .

Nombres continúan apareciendo en más y más cartas que se agolpan dispersas en carpetas interminables. El exilio fue parte de la familia Sotoconil, del círculo de amistades; central en los trabajos políticos que desarrollaban. Destierro, asilo, retorno, preocupaciones axiales de la militancia, del quehacer artístico, de la vida. A partir de todo ello, la relación entre Rubén Sotoconil con "Araucaria de Chile" no pudo parecer inesperada. Activo militante comunista vinculado a las artes, escribió para la revista en nueve números $(1,6,9,10,13$, $16,17,23,45)$ con distintos seudónimos y sobre diversas temáticas. Roberto Pailahueque ("seudónimo del escritor chileno residente en la actualidad en el país") ${ }^{48}$, Ramón de Guzmán, Arnold Sutcliffe, Álvaro y Rigoberto Mulchén fueron sus 'chapas', las que usó para publicar sobre teatro y otros temas contingentes como salud, educación y represión. Se extendía la necesidad de despojarse del nombre propio, para poder decir, develar.

${ }^{44}$ Ibid., p. 247

${ }^{45}$ Rosario. Carta de Madrid. 16/11/1977

${ }^{46}$ Carmen. Carta de Caracas. 27/06/1979

${ }^{47}$ Ana. Carta de Madrid. 18/05/ 1980

${ }^{48}$ Roberto Pailahueque, "Pedro de la Barra ha muerto en el exilio". Araucaria de Chile. №1, Paris, 1978, p. 189-190 
Su primer artículo fue "Pedro de la Barra ha muerto en el exilio" en el que rememora la vida $\mathrm{y}$ aportes fundamentales del director y fundador del Teatro Experimental de la Universidad de Chile. Como un observador distante e imparcial describe los procesos en los que estuvo del todo implicado: la renovación del teatro, el Frente Popular y cómo no, la trágica muerte en el destierro del que habría sido su camarada. Con desazón se cuestiona de forma retórica: “¿Por qué tuvo que morir fuera de Chile? ¿Por qué su familia fue reducida y exiliada?" 49 . Invadido por la nostalgia, culmina su texto con una dedicatoria que no tiene contestación: "Querido Pedro, ansiando volver a caminar por las calles de Antofagasta o Concepción, chapalear en el Bío-Bío o en las aguas del Estrecho, morir con los suyos y renacer con ellos" $" 50$.

El número 6 de la Revista, contiene dos textos de Sotoconil. Allí, Ramón de Guzmán, segundo seudónimo de Sotoconil, publica el artículo "El teatro experimental”. Transcribe una entrevista con tres de sus fundadores: los actores Roberto Parada ${ }^{51}$, María Maluenda y el mismo Rubén Sotoconil, además de presentar con extensión sus fundamentos, principales luchas, fundadores, entre otros asuntos ${ }^{52}$. Se define al Teatro Experimental como un proyecto "antifascista" de "organización democrática, abierta, disciplinada y progresista" 53 . Menciona, asimismo, a compañeros co-fundadores que han muerto y otros que han sido exiliados por su conocida militancia e inclinaciones políticas. Todo ello, parece ser fragmentos anticipados de lo que sería el libro "20 años de Teatro Experimental" escrito por Sotoconil y publicado años después.

En el mismo número, publica "Teatro de creación colectiva" esta vez rubricado por Arnold Sutcliffe, otro de sus alias. En este artículo manifiesta su interés por reivindicar la historicidad política del teatro y su capacidad concientizadora, transformadora. Según señala, un rol constitutivo del teatro ha sido "motivar a la gente para pensar y actuar, para tomar conciencia de los problemas sociales más apremiantes y apuntar a la salida o aunque más no sea, a un cambio de actitud ante los monstruos" ${ }^{25}$. En este sentido, percibe a la Unidad Popular como espacio preferente para materializar un arte "que incorpore la lucha social, las conquistas de los trabajadores" 55 en teatros poblacionales, periféricos, sindicales que exploren escenografías-plazas, fábricas, centros obreros. Sobre la dictadura, señala que "el teatro de creación colectiva ha mostrado ser una forma artística que toma partido en la vida y en el trabajo, a pesar de las coacciones del medio" "56. En este contexto brotan las significativas experiencias del Taller de Investigación Teatral de la Universidad Católica, la Acción Cultural Universitaria, el Teatro Ictus, Imagen, Taller de Investigación Teatral y la Compañía Salcedo-Vadell. El arte dramático tendría por entonces a los ojos de Sotoconil, la misión de dar cuenta lo que pretende permanecer oculto y no menos que entibiar "el alma

\footnotetext{
${ }^{49}$ Ibid, p. 190

${ }^{50}$ Idem.

${ }^{51}$ Padre de José Manuel Parada, sociólogo asesinado en Caso Degollados en 1985

${ }^{52}$ Ramón de Guzmán, “Teatro Experimental”. Araucaria de Chile, №6, Madrid, 1979.

${ }^{53}$ Ibid.,p. 113

${ }^{54}$ Sutcliffe, Arnold. "Teatro de creación colectiva". Araucaria de Chile, N 6, Madrid, 1979, p. 149

${ }^{55}$ Ibid.,p. 150

${ }^{56}$ Ibid.,p. 150
} 
aterida de nuestro pueblo, aclarando su confusión, orientando sus pensamientos y su conducta" 57

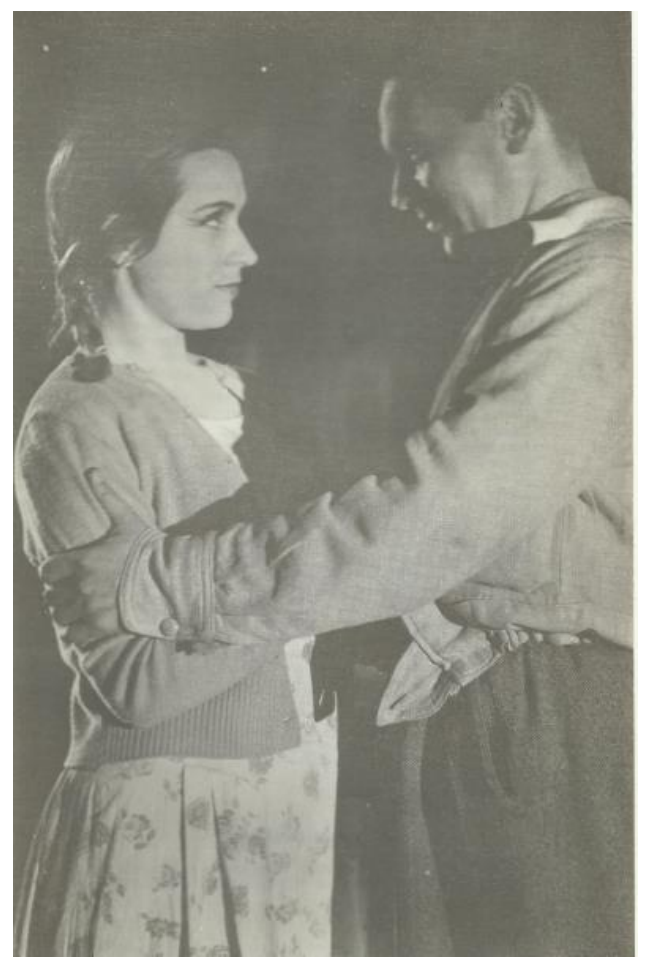

Rubén Sotoconil y María Teresa Fricke. Fuente: Revista Araucaria Nº6

Muy distinto al tenor de los otros artículos es "La medicina como negocio" firmada por Roberto Pailahueque, publicado en el número 9 de la revista. En él se devela la instalación de una dictadura que le parece inclemente y que ya para entonces, impone el aparato de la atención privada: "Mal anda la salud de los chilenos. La cabeza nos duele a todos a causa de los numerosos virus de hambre, dictadura y economía del libre mercado" "58. En este escrito, Sotoconil -o Pailahueque- deja de encarnar al actor, para volverse sujeto denunciante de la contingencia y testigo del proceso inopinado de privatización de la salud. En el número 10, se halla un escrito firmado por Álvaro Mulchén, cuarto seudónimo de Sotoconil. Se titula "Apuntes" y su epígrafe reza: "Estas notas han sido tomadas de hechos de la vida real. Sólo los nombres propios han sido cambiados"59. Aquí, el autor recopila y transcribe experiencias de individuos distintos que refieren a su vida en dictadura: detenciones, desapariciones, vejaciones, conjugadas con sentimientos de asfixia, desilusiones y esperanzas. Dan sus testimonios un folklorista, un empleado, una pintora, una abuela y un profesor, "gente común" tiene aquí su sitio de denuncia y rebeldía. Las identidades son ocultadas para, otra vez, poder decir sin reservas los dolores y horrores que ofrece para ellos el gobierno autoritario. Orlando dice "He vivido estos años con la muerte, bajo la amenaza de desaparecer de repente yendo calle abajo (...) Una existencia sin raíces

\footnotetext{
${ }^{57}$ Ibid., p. 152

${ }^{58}$ Roberto Pailahueque, "La medicina como negocio". Araucaria de Chile, No 9, Madrid, 1980, p. 207

59 Álvaro Mulchén, "La historia vivida”. Araucaria de Chile No 10, Madrid, 1980, p. 53
} 
ni futuro, una larga pesadilla de vejaciones"60. Cecilia, señala: "Me han cambiado el alma estos fascistas (...) Me han cambiado el mundo armonioso en su tumulto y me han creado sentimientos destructivos. Quisiera volver a respirar"61. Estos enunciados colectivos recopilados por Sotoconil, revelan nuevas aristas del insilio con su relego y proximidad a la muerte. A pesar del sinsentido y la herida irrevocable, estas voces buscan esperanzas, traman solidaridades y preservan su dignidad ante la bestialidad de un golpe que les "remeció las entrañas"

En la Araucaria del primer semestre de 1981, Rigoberto Mulchén, un quinto rostro de Sotoconil, escribe "Chiloé a la hora del fascismo", crónica que releva la cultura y tradiciones locales de una isla que se ve confrontada a las nuevas y adversas condiciones económicas. Detalla algunas organizaciones culturales que persisten en un contexto de "saqueo, la destrucción sistemática, la irracionalidad. Con características que lindan con lo demencial" "63. Como en otros de sus textos se expresa un telos que se avizora al final del camino y que deja abierta la esperanza: "Luego llegaron los militares, y hoy la pobreza es mayor, la tristeza es mayor. Pero de algún modo, la gente preparará el fuego y la tierra para hacerla florecer" 64 .

En uno de sus últimos artículos escritos para la Revista, Sotoconil vuelve sobre su tema de vida e investigación: el Teatro Experimental. Allí expone aspectos distintos del publicado en 1979 y, esta vez, sin seudónimo. Rememora el origen, la formación del CADIP (Centro de Arte Dramático del Instituto Pedagógico), narra anécdotas, los primeros ensayos. A modo de recuento, da cuenta de los aportes de la experiencia del Teatro Experimental: la modernización, investigación teatral, divulgación del teatro en espacios populares, la creación de una Escuela de Teatro profesional y las prácticas asambleístas que adoptaron para su funcionamiento ${ }^{65}$.

Varios años más tarde, en 1989 escribiría su último texto para la revista: "La revolución francesa. Hechos y etapas de su desarrollo" en ocasión de la conmemoración a los doscientos años de ocurrida. En un extensísimo texto de tono más bien descriptivo, expone con pormenores, cifras, guarismos las fases de la revolución, siempre desde una perspectiva clasista. En un relato cronológico, articula su texto con las concepciones binarias de "progresista" o "reaccionario", por medio de decenas de referencias, que incluyen a Lenin y lo corona - como no- con una cita de "El 18 Brumario de Luis Bonaparte" de Carlos $\operatorname{Marx}^{66}$.

\footnotetext{
${ }^{60}$ Ibid.,p. 54

${ }^{61}$ Ibid.,p. 55

62 Ibid.,p. 56

${ }^{63}$ Rigoberto Mulchén, "Chiloé en la hora del fascismo". Araucaria de Chile $\mathrm{N}^{\circ}$ 13, Madrid, 1981, p. 18

${ }^{64}$ Ibid.,p. 20

${ }^{65}$ Rubén Sotoconil, "El Teatro Experimental”. Araucaria de Chile $\mathrm{N}^{\circ} 16$, Madrid, 1981, p. 195

${ }^{66}$ Rubén Sotoconil, "La revolución francesa. Hechos y etapas de su desarrollo". Araucaria de Chile N 46, Madrid, 1989, p. 67
} 
Particular parece que no exista en ningún número de Araucaria de Chile algún texto sobre el exilio interior o insilio. Torrentes de escritos hablan del drama del destierro en todos sus carices, incluido el retorno, pero no se considera la voz de quienes sobreviven 'dentro', a excepción del escrito precitado de Sotoconil. Se pesquisa un testimonio fragmentario, acaso único e inaudito:

Es doloroso constatar que para los chilenos 'de adentro' esta comunicación o acercamiento es difícil y remota: nos seguimos manejando con imágenes que el tiempo y la evolución de las personas hacen parecer caducas, por eso es muy enriquecedor poder por medio de Araucaria saber no sólo que siguen produciendo sino leer lo que producen. Inmersos en un mundo cultural chato y alienado, los artículos de Araucaria son aire fresco que trae no sólo nostalgias, sino también

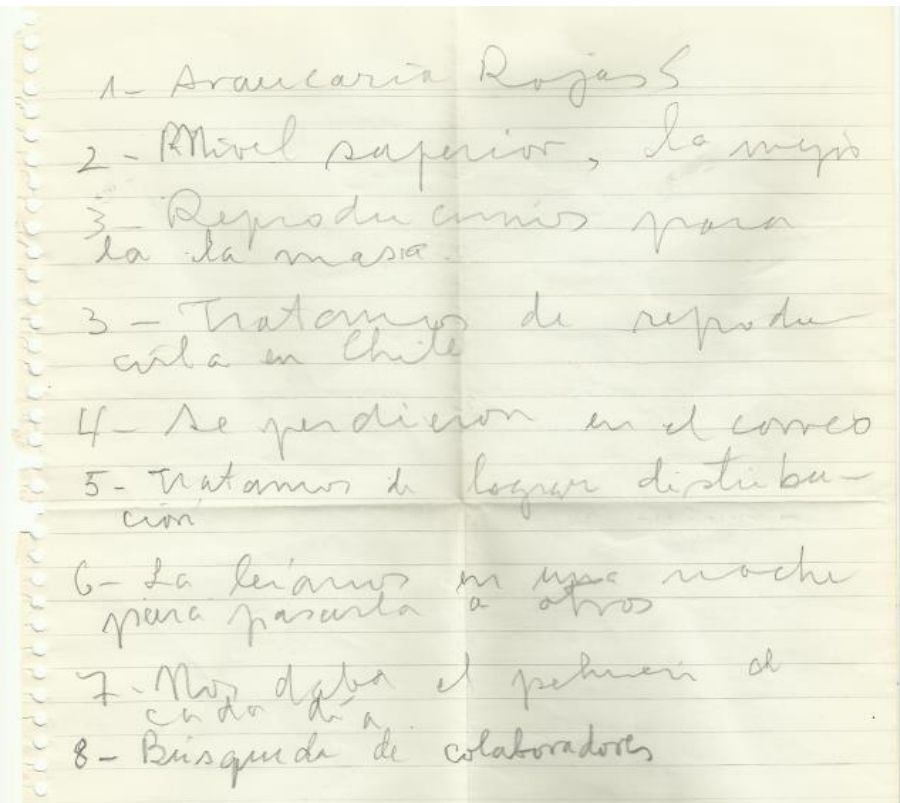
noticias de un mundo que no se detiene y sigue creciendo ${ }^{67}$.

Estas palabras designan con fidelidad el sentimiento de los invisibles insiliados. La revista representó una ventana, válvula, puente conector entre el dentro y todos los afuera que en ella se plasmaban. "Araucaria" entraba gracias a figuras que, en la penumbra, la recibían, portaban, propagaban. Sotoconil escribió para ella, pero más que todo, gestionó su traída y propaló su desperdigue. La condición de clandestinidad, censura y exoneración política, se conjugaron con la activación continua, ininterrumpida de la militancia, que permitió su recepción y divulgación.

\footnotetext{
Manuscrito referido a Revista Araucaria. Fuente: Archivo personal Rubén Sotoconil
}

Los problemas que esta misión acarreaba decían relación con la calidad, recepción y eventual pérdida. Dentro de Chile, la revista cobraba ribetes distintos, en tanto debía transmitirse a otros en secreto, como indica este manuscrito en el punto 6, "la leíamos en una noche para pasarla a otros", buscar colaboradores y asegurar su correcta y expedita recepción.

\footnotetext{
${ }^{67}$ Una chilena de adentro, "De los lectores". Araucaria de Chile, $\mathrm{N}^{\circ} 23$, Madrid, 1983, p. 8.
} 
Para ocultar la referencia directa a la revista, Sotoconil utiliza como 'chapa' el nombre de su nieta y partir de allí despliega desafíos y digresiones. Entre los deberes descritos, se lee lo representa "Araucaria" en todos sus sentidos y acepciones: "Nos daba el pehuén de cada día".

\section{Reflexiones finales}

Una hebra común parece extenderse por todos los intersticios y avatares de la vida de Rubén Sotoconil: su temprana adscripción al Partido Comunista de Chile marcaría sus trayectorias a fuego. Tanto el florecimiento artístico de la Unidad Popular como la hecatombe que representó del golpe de Estado, revistieron para Sotoconil hitos axiales en su existencia. La dictadura impuso en adelante exilio, represión, censura y exoneración para él, su familia, amigos y camaradas; todos forzados a replantear sus derroteros cotidianos. Tanto su participación en el Teatro Experimental, como el Teatro Familiar de Barrio, sus escritos y artículos en Revista Araucaria, parecen tener una misma fuente: la reivindicación de politicidad de su quehacer artístico. El teatro, el Partido, sus investigaciones y escritos, obedecen a la necesidad de fundar constantemente un quehacer contingente, resonante del presente.

El año de su muerte continuaba manifestando la misma inquietud y compromiso político, en una misiva enviada al pintor José Balmes:

Es preciso salir y ya no puedo subir por esas calles cuesta arriba. Es de rigor luchar y mis fuerzas se acaban apenas doy un paso. Hay que organizarse, recuperar la conciencia de futuro que siempre nos galvanizó. Ordenar la utopía que nos arde en el pecho: aventar la injusticia, borrar nuestras miserias, eliminar el hambre en todas sus grafías, hacer de cada día una risa de todos y con todo. ${ }^{68}$

Así las cosas, Rubén Sotoconil se presenta como una pieza fundamental para el teatro chileno del siglo XX. Fue actor destacado, prolífico pedagogo teatral, traductor de oficio, agudo fotógrafo y estudioso de un sinfín de temas. Autor de los libros "Teatro en la escuela" (1952), "Teatro en un acto" (1959), "Teatro escolar" (1965), "Teatro todo el año" (1971), "La voz hablada" (1971), "Manual y antología de teatro escolar" (1984), "Veinte años de teatro experimental" (1991), "Teatro escolar, 21 obras" (1992), "Prontuario del teatro" (1998), "Almanaque teatral” (2002). Películas, obras de teatro y teleseries se cuentan entre sus incursiones.

Perdió su nombre y su identidad habitual para crear nuevas formas de enunciación, nuevas tierras que habitar y así desplegar su potencia liberadora. Desde la escritura seudónima, erigió puentes y ensambló a las que estaban destinadas a ser islas. La obra Sotoconil continúa en el mismo lugar invisible al que la dictadura lo habría relegado y el silenciamiento de su figura en los tiempos autoritarios parece haberse perpetuado. Que esta pequeña aproximación opere como mínimo reconocimiento, recuerdo y justicia a todo lo que sus afanes merecieron y merecen. El 12 de marzo de 2002 murió en su casa, días antes

\footnotetext{
${ }^{68}$ Rubén Sotoconil, Carta a José Balmes, Archivo Personal de Mireya Moreno, Santiago 2002.
} 
de cumplir 85 años y cinco días después de haber lanzado su último libro "Almanaque Teatral".

\section{Bibliografía}

\section{Libros:}

Amorós, Mario. Allende. La Biografía. Santiago: Eds. B, 2013.

De la Fuente, María. Teatro Familiar de Barrio: Una experiencia de lucha, Imp. Walter Letelier, Santiago 2002.

Hurtado, María de la Luz y Ochsenius, Carlos. Teatro Ictus, Santiago: Ed. CENECA

Ireland Tomás y Rivera Francisco eds., La UTE vive. Memorias y testimonios de la reforma universitaria en la Universidad Técnica del Estado. Chile 1961/1973, Santiago: Ed. USACH, 2016,

Marx, Karl. Manuscritos económicos y filosóficos, Santiago: Ed. Austral, 1960

Orellana, Carlos. Araucaria de Chile. Índice general (1978-1989), Santiago: Ed. Del Litoral. 1992

Prudant, Elisabeth. Y entonces estaban ellas. Memoria $(s)$ de las Mujeres Democráticas durante la dictadura, Santiago: Ed. Ceibo, 2013

Salabert, Miguel. El exilio interior, Barcelona: Ed. Anthropos, 1988

Sotoconil, Rubén. 20 años de Teatro Experimental, Caracas: Ed. Gráficas Internacional, 1991.

Teitelboim, Volodia. En el país prohibido. Santiago: Ed. Sudamericana, 1998.

Zapata, Lina. Ocho vidas para ser actuadas, Santiago: Ed. Hernán Godoy, 2003.

\section{Artículos de libro}

Albornoz, Cesar. "La cultura en la Unidad Popular: Porque esta vez no se trata de cambiar un presidente" en Pinto, Julio ed., Cuando hicimos historia: La experiencia de la Unidad Popular, Santiago: Ed. LOM, 2005.

Illanes, María Angélica. "El cuerpo nuestro de cada día": El pueblo como experiencia emancipatoria en los tiempos de la Unidad Popular" en, Pinto, Julio ed., Cuando hicimos historia: La experiencia de la Unidad Popular, Santiago: Ed. LOM, 2005. 
Lepeley, Oscar. "Avatares del teatro chileno contestatario durante los primeros años de la dictadura militar" en Heidrun Adler, et. Al., Resistencia y poder. Teatro en Chile, Madrid: Ed. Iberoamericana, 2000.

Norambuena, Carmen. "Exilio y retorno. Chile 1973-1994”, en Garcés, Mario y Milos Pedro et al. Memoria para un nuevo siglo. Chile, miradas a la segunda mitad del siglo XX. Santiago: ECOS-Depto. de Historia. LOM, 2000

Villegas, Juan. "Discursos teatrales en Chile en la segunda mitad del siglo XX" en Heidrun Adler, et. Al., Resistencia y poder. Teatro en Chile, Madrid: Ed. Iberoamericana, 2000.

\section{Artículos de revista}

Alegría, Fernando. "La novela chilena del exilio interior", en Revista Chilena de Literatura, $\mathrm{N}^{\circ}$ 42, Santiago, 1993.

Cancino, Hugo. "Exilio, chileno e historia. Contribución a un debate sobre los problemas teórico- metodológicos de una investigación historiográfica sobre nuestro exilio". Centro de estudios Miguel Enríquez CEME. Santiago, 2001.

De Guzmán, Ramón. “Teatro Experimental”. Araucaria de Chile, º6, Madrid, 1979

Muñoz, Diego. "Teatro poblacional chileno (1978 1983)". Araucaria de Chile $\mathrm{N}^{\circ}$ 31, Madrid, 1985.

Nómez, Naín. “Transformaciones de la poesía chilena entre 1973 y 1988”, Estudios filológicos $\mathrm{N}^{\circ}$ 42, Valdivia, 2007

Mulchén, Álvaro. "La historia vivida”. Araucaria de Chile No 10, Madrid, 1980.

Mulchén, Rigoberto. "Chiloé en la hora del fascismo". Araucaria de Chile $\mathrm{N}^{\circ}$ 13, Madrid, 1981.

Norambuena, Carmen. "El exilio chileno río profundo de la cultura Iberoamericana" en Revista Sociohistórica: Cuadernos del Cish, Buenos Aires, 2008.

Pailahueque, Roberto. "Pedro de la Barra ha muerto en el exilio". Araucaria de Chile. $\mathrm{N}^{\circ} 1$ Madrid, 1978.

Pailahueque, Roberto. "La medicina como negocio". Araucaria de Chile, № 9, Madrid, 1980.

Rojo, Grinor. "Teatro chileno bajo el fascismo". Araucaria de Chile № 22, Madrid, 1983.

Sutcliffe, Arnold. "Teatro de creación colectiva". Araucaria de Chile, № 6, Madrid, 1979.

Sotoconil, Rubén. “El Teatro Experimental”. Araucaria de Chile $\mathrm{N}^{\circ}$ 16, Madrid, 1981 
Sotoconil, Rubén. "La revolución francesa. Hechos y etapas de su desarrollo". Araucaria de Chile $\mathrm{N}^{\circ}$ 45, Madrid, 1989.

Sotomayor, Sibila. "Una escena truncada: historia de la Escuela de Teatro de la Universidad Austral de Chile (1970-1976)”, Panambí, N², Valparaíso, 2016.

Una chilena de adentro, "De los lectores". Araucaria de Chile, №23, Madrid, 1983.

\section{Artículos de periódicos}

“Deja que los perros ladren”, Última Hora, 21 de septiembre de 1961

\section{Entrevista}

Entrevista a Rubén Sotoconil, realizada por Priscilla Gutiérrez, febrero 2002

Entrevista a Mireya Moreno, realizada por la autora, marzo 2016.

\section{Manuscritos:}

Rosario. Carta de Madrid. 16/11/1977

Carmen. Carta de Caracas. 27/06/1979

Ana. Carta de Madrid. 18/05/ 1980

Rubén Sotoconil, Carta a José Balmes, Archivo Personal de Mireya Moreno, Santiago 2002.

\section{Audiovisuales}

Museo de la Memoria y los Derechos Humanos, Teatro Familiar de Barrio, Santiago: Museo de la Memoria y los Derechos Humanos, 2011.

\section{Tesis}

Christian García Medel, El rol sociopolítico del teatro durante el Régimen Militar, Tesis para optar al grado de periodista Universidad Academia de Humanismo Cristiano, Santiago, 2011 